\title{
ANÁLISE EPIDEMIOLÓGICA DE ÓBITOS DOMICILIARES E HOSPITALARES DURANTE A PANDEMIA DA COVID-19 NO ESTADO DO PARANÁ
}

\author{
EPIDEMIOLOGIC ANALYSIS OF HOME AND HOSPITAL DEATHS DURING \\ THE COVID-19 PANDEMIC IN THE STATE OF PARANÁ
}

Liria Maria Daldoso Silva ${ }^{1 *}$, Luisa Miranda Loidi ${ }^{1}$, Mariana Cardoso Camilo", João Pedro Zuin Do Amaral².

${ }^{1}$ UNINGÁ - Centro Universitário Ingá, Maringá, PR, Brasil.

${ }^{2}$ Hospital Angelina Caron, Curitiba, PR, Brasil.

*liriadaldoso@gmail.com

\section{RESUMO}

O novo coronavírus SARS-COV-2, causador da infecção viral denominada COVID-19, pode causar desde quadros assintomáticos até quadros complicados e com prognóstico desfavorável. Além disso, a transmissão do vírus acontece de maneira horizontal entre indivíduos, podendo ocorrer por meio de aerossóis, contato por fômites, oral-fecal, por contato de mãos com consecutivo direcionamento delas a mucosas. Consequentemente, a fim de conter a disseminação da doença, o isolamento social é uma medida que está sendo amplamente adotada, porém o isolamento associado ao receio dos indivíduos em procurarem assistência médica pode ter um reflexo negativo em outras patologias, como sepse e acidente vascular cerebral (AVC). Este trabalho objetivou uma avaliação epidemiológica dos óbitos ocorridos de março a agosto de 2020, período referente a pandemia pelo COVID-19, no estado do Paraná. Durante a pesquisa, foram utilizados dados do Portal da Transparência do Registro Civil para análise das causas dos óbitos. Diante dos resultados obtidos é possível constatar que houve mais de 1.161 mortes domiciliares de março a agosto de 2020 no estado do Paraná, quando comparado ao mesmo período em 2019, com aumento nas mortes domiciliares por septicemia (45\%), síndrome respiratória aguda grave (200\%), AVC (21\%), e causas cardiovasculares inespecíficas $(1,81 \%)$. Já em relação aos óbitos hospitalares foi averiguado queda das mortes por AVC (3,36\%) e sepse (39\%), porém, com aumento dos óbitos por causas indeterminadas $(12,6 \%)$, causas cardiovasculares inespecíficas (13\%), e com destaque para síndrome respiratória aguda grave (161\%). Em relação ao sexo, a sepse foi o fator que mais levou a óbito do sexo feminino, enquanto no sexo masculino foi devido a pneumonia. Além disso, em relação à faixa etária, as mulheres entre os 80 a 89 anos foram mais acometidas, e os homens entre 70 a 79 anos, independentemente do local do óbito. A luz do exposto, evidencia-se que houve aumento de mortes domiciliares e redução das mortes hospitalares por AVC e sepse, no Paraná, em 2020, em meio ao contexto de pandemia. Acredita-se que o crescente número de mortes em domicílio por essas doenças esteja associado ao receio do paciente de procurar assistência médica e se infectar pelo coronavírus, uma vez que as faixas etárias que mais foram a óbito, também são faixas etárias de maior vulnerabilidade ao vírus. Diante disso, nota-se necessidade de se ter um olhar mais apurado para 
doenças e manifestações que requerem acompanhamento médico contínuo presente nos hospitais, como nos casos das patologias citadas nesse trabalho. Nesse sentido, estudos similares em outros estados seriam interessantes para analisar se esse padrão se repete, de modo a certificar a implicação nacional do COVID-19 sobre o aumento das mortes domiciliares.

Palavras-chave: COVID-19. Doenças cardiovasculares. Doenças respiratórias. Óbitos. Pandemia. 